\title{
A Novel Mega-stable Chaotic Circuit
}

\author{
Viet-Thanh PHAM ${ }^{1,2}$, Dalia Sami ALI ${ }^{3}$, Nadia M.G. AL-SAIDI ${ }^{4}$, Karthikeyan RAJAGOPAL ${ }^{5}$, \\ Fawaz E. ALSAADI ${ }^{6}$, Sajad JAFARI ${ }^{7}$
}

${ }^{1}$ Faculty of Electrical and Electronic Engineering, Phenikaa Institute for Advanced Study (PIAS), Phenikaa University, Yen Nghia, Ha Dong district, Hanoi 100000, Vietnam

${ }^{2}$ Phenikaa Research and Technology Institute (PRATI), A\&A Green Phoenix Group, 167 Hoang Ngan, Hanoi, Vietnam

${ }^{3}$ Dept. of Civil Engineering, Al-Mansour university college, Baghdad, Iraq

${ }^{4}$ Dept. of Applied Sciences, University of Technology, Baghdad, Iraq

${ }^{5}$ Center for Nonlinear Dynamics, Institute of Research and Development, Defence University, Ethiopia

${ }^{6}$ Dept. of Information Technology, Faculty of Computing and IT, King Abdulaziz University, Jeddah, Saudi Arabia

${ }^{7}$ Dept. of Biomedical Engineering, Amirkabir University of Technology, 424 Hafez Ave., Tehran 15875-4413, Iran

thanh.phamviet@phenikaa-uni.edu.vn, dalia.sami@muc.edu.iq, nadiamg08@gmail.com,rkarthiekeyan@gmail.com, fawazkau@gmail.com, sajadjafari83@gmail.com

Submitted September 27, 2019 / Accepted January 18, 2020

\begin{abstract}
In recent years designing new multistable chaotic oscillators has been of noticeable interest. A multistable system is a double-edged sword which can have many benefits in some applications while in some other situations they can be even dangerous. In this paper, we introduce a new multistable two-dimensional oscillator. The forced version of this new oscillator can exhibit chaotic solutions which makes it much more exciting. Also, another scarce feature of this system is the complex basins of attraction for the infinite coexisting attractors. Some initial conditions can escape the whirlpools of nearby attractors and settle down in faraway destinations. The dynamical properties of this new system are investigated by the help of equilibria analysis, bifurcation diagram, Lyapunov exponents' spectrum, and the plot of basins of attraction. The feasibility of the proposed system is also verified through circuit implementation.
\end{abstract}

\section{Keywords}

Multistability, chaotic oscillators, basin of attraction, coexisting attractors

\section{Introduction}

Multistability is a critical phenomenon in dynamical systems [1]. Sometimes multistability is undesirable. That is the case when it is essential for us to have the system in one specific attractor, but due to even small changes in parameters or external disturbance, the system's state exits from that attractor and fall into another coexisting attractor. On the other hand, it allows adaptability in the system's administration without modifying parameters. It would be possible with the appropriate control tactics to induce switching between different coexisting states [1], [2].
Recently there has been growing attention in finding chaotic systems with special qualities. Systems with no equilibrium [3], [4], with stable equilibria [5], [6], with curves of equilibria [7-9], with surface of equilibria [10-12], with multi-scroll attractors [13], with hidden attractors [14], [15], with amplitude control [16], [17], with simplest form, having hyperchaos [18-20], having fractional order form [21-23], with topological horseshoes [24], [25], and with extreme multistability [26-29], are examples of them. Another major category of chaotic systems includes periodically-forced nonlinear oscillators [30]. Almost all conventional chaotic systems are systems with a finite number of fixed points [30]. Recent researches have laid a platform to formulate systems with an infinite number of equilibrium points [31], [32] Local features of such equilibrium points may or may not influence the global response of the chaotic system. A very recent category of chaotic systems are systems with mega-stability. Mega-stability is the coexistence of a countable infinity of nested attractors in a dynamical system [33]. In [34], megastability found in a quasi-periodically forced system exhibiting. A new mega-stable nonlinear oscillator with infinite islands of self-excited and hidden attractors reported in [35]. A new oscillator with infinite coexisting asymmetric attractors introduced in [31]. Some other such examples have been proposed recently [36-39].

In this paper, based on the systems in [40] we propose a revised oscillator with an infinite number of coexisting limit cycles. Interestingly, the forced version of this new oscillator can display chaotic solutions. In this oscillator, many of the initial limit cycles vanish while some new limit cycles and strange attractors are born (depending on the parameters). Also, another infrequent feature of this system is the complex basins of attraction for the infinite coexisting attractors. Some initial conditions can avoid the whirlpools of nearby attractors and settle down in faraway destinations. In the next 
section, the new oscillator is introduced and investigated. In Sec. 3, the forced version of this oscillator is presented, and its dynamical properties are examined by the help of the bifurcation diagram, Lyapunov exponents' spectrum, and the plot of basins of attraction. Also with a circuit implementation, its feasibility for possible engineering application is displayed in Sec. 4. Finally, discussion and conclusion are given in Sec. 5. It should be noted that we have used MATLAB for all the simulations. Attractors detected manually by trial and error. Limit cycles were distinguished from chaotic attractors by the help of Lyapunov exponents, using Wolf algorithm [41].

\section{The New Oscillator}

Consider system (1),

$$
\begin{aligned}
& \dot{x}=y, \\
& \dot{y}=-\cos (a x)+b y \cos (x) .
\end{aligned}
$$

This system is a modification of system (2) [40]:

$$
\begin{aligned}
& \dot{x}=y, \\
& \dot{y}=-x+y \cos (x) .
\end{aligned}
$$

The number of equilibrium points in system (1) is infinite. They are located in $\left(\frac{(2 k-1) \pi}{2 a}, 0\right)$ where $k$ is an arbitrary integer number.

Considering $a=0.3$ and $b=-0.1$ (these values have been selected to find chaotic solutions in the forced version of system (1), which will be discussed in next sections), we focus on system (3):

$$
\begin{aligned}
& \dot{x}=y, \\
& \dot{y}=-\cos (0.3 x)-0.1 y \cos (x) .
\end{aligned}
$$

The Jacobian of the above system in its equilibria is:

$$
\begin{aligned}
& J=\left[\begin{array}{cc}
0 & 1 \\
0.3 \sin (0.3 x)+0.1 y \sin (x) & -0.1 \cos (x)
\end{array}\right] \\
& \stackrel{(x, y)=\left(\frac{5(2 k-1) \pi}{3}, 0\right)}{\longrightarrow}
\end{aligned}
$$

$$
\begin{aligned}
J & =\left[\begin{array}{cc}
0 & 1 \\
0.3 \sin \left(\frac{(2 k-1) \pi}{2}\right) & -0.1 \cos \left(\frac{5(2 k-1) \pi}{3}\right)
\end{array}\right] \\
& =\left[\begin{array}{cc}
0 & 1 \\
0.3(-1)^{k+1} & -0.1 \cos \left(\frac{5(2 k-1) \pi}{3}\right)
\end{array}\right] .
\end{aligned}
$$

So, the eigenvalues will be:

$$
\begin{aligned}
& |\lambda I-J|=0 \rightarrow \\
& \left|\begin{array}{cc}
\lambda & -1 \\
-0.3(-1)^{k+1} & \lambda+0.1 \cos \left(\frac{5(2 k-1) \pi}{3}\right)
\end{array}\right|=0 \rightarrow \\
& \lambda^{2}+0.1 \cos \left(\frac{5(2 k-1) \pi}{3}\right) \lambda-0.3(-1)^{k+1}=0 \rightarrow \\
& \lambda_{1,2}=\frac{-0.1 \cos \left(\frac{5(2 k-1) \pi}{3}\right) \pm \sqrt{\left(0.1 \cos \left(\frac{5(2 k-1) \pi}{3}\right)\right)^{2}+1.2(-1)^{k+1}}}{2} .
\end{aligned}
$$

\footnotetext{
Fig. 2. Basin of attraction plot for the 6 limit cycle attractors and 4 stable equilibria shown in Fig.1. Initial conditions in the white area go to attractors outside this frame. This figure is obtained by a grid of $200 \times 200$ initial conditions. The color of each smooth area belongs to the attractor inside it.
}

Thus, any equilibrium in which both $\operatorname{Real}\left(\lambda_{1,2}\right)<0$ is stable. Otherwise the equilibrium is unstable.

Figure 1 is a plot of trajectories in system (3) for 51 different initial conditions located on the $x$-axis (from $x=-50$ to $x=+50$ with steps equal to 2 ). The stable equilibrium points are shown by blue circles, while unstable equilibrium points are given by red crosses. Each trajectory is plotted for 1000 seconds. The first 800 seconds of each trajectory is plotted with green dots, showing the transient parts of trajectories. The last 200 seconds of each trajectory is plotted with thick black lines, showing the steady state of that trajectory.

It can be seen that six limit cycles and four stable equilibria coexist in the shown area (note that they are examples of an infinite number of attractors around the $x$-axis). The basin of attraction for these attractors can be seen in Fig. 2 .

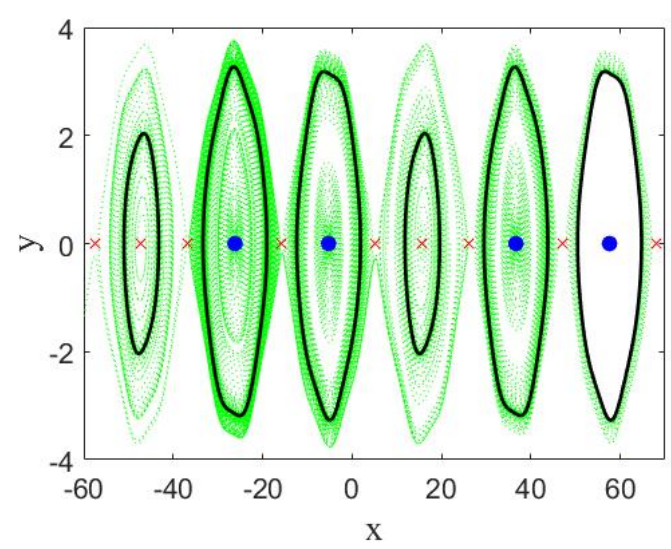

Fig. 1. Trajectories in system (3) for 51 initial conditions located on the $x$-axis (from $x=-50$ to $x=+50$ with steps equal to 2). The stable equilibrium points are shown by blue circles, while unstable equilibrium points are displayed by red crosses. The transient parts of trajectories are shown by green dots. The attractors outside this frame and 4 stable equilibria can be observed in this plot). For and 4 stable equilibria can
more details see the text.

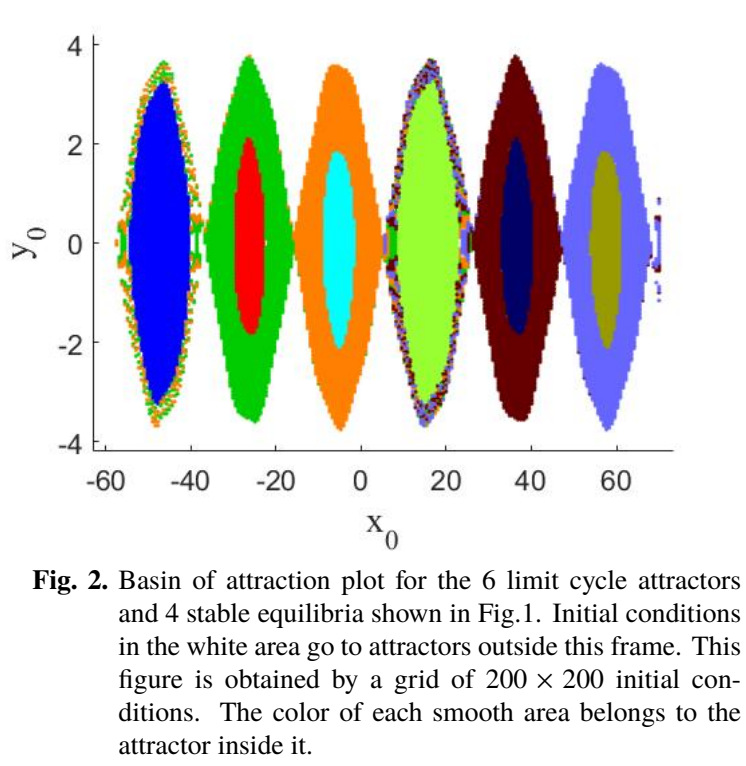




\section{The Forced Chaotic Oscillator}

By adding a periodic forcing function to system (3), a new oscillator is introduced:

$$
\begin{aligned}
& \dot{x}=y, \\
& \dot{y}=-\cos (0.3 x)-0.1 y \cos (x)+A \sin (\omega t) .
\end{aligned}
$$

We are interested in finding chaotic solutions in this system. Different combinations of $(A, \omega)$ may result in chaotic solutions. Selecting $\omega=0.5$, we choose $A$ as the bifurcation parameter. Figure 3 shows the bifurcation diagram and Figure 4 shows the Lyapunov exponents of system (6) versus $A$. We can see that in $A$ between zero and approximately 0.04 , the dynamical behavior of system (6) is attracting torus (two zero and one negative Lyapunov exponents [30]). After that, suddenly the solution is converging to a stable equilibrium (one zero and two negative Lyapunov exponents). In the area after $A=0.07$ some chaotic solutions are born containing periodic windows. Some period doubling route to chaos can be observed in those areas.

Choosing $A=0.1$ (and $\omega=0.5$ ) from the chaotic region, we continue our analysis. Figure 6 shows impressive features of system (6). This is a plot of coexisting attractors for the same initial conditions used in plotting Fig. 1. For a better demonstration of this figure, we have zoomed some parts of it and shown them in Fig. 7. Also, the time-series and attractor for initial condition $(1,1)$ are plotted in Fig. 5. In Figs. 6 and 7, it can be observed that the initial limit cycles are now replaced by some coexisting strange attractors and new limit cycles. It is interesting that some new limit cycles are the results of merging old limit cycles. Also, a unique phenomenon can be detected in Fig. 6. Some initial conditions are not get trapped in nearby attractors. Instead, they travel far away and settle down in an unexpected attractor.

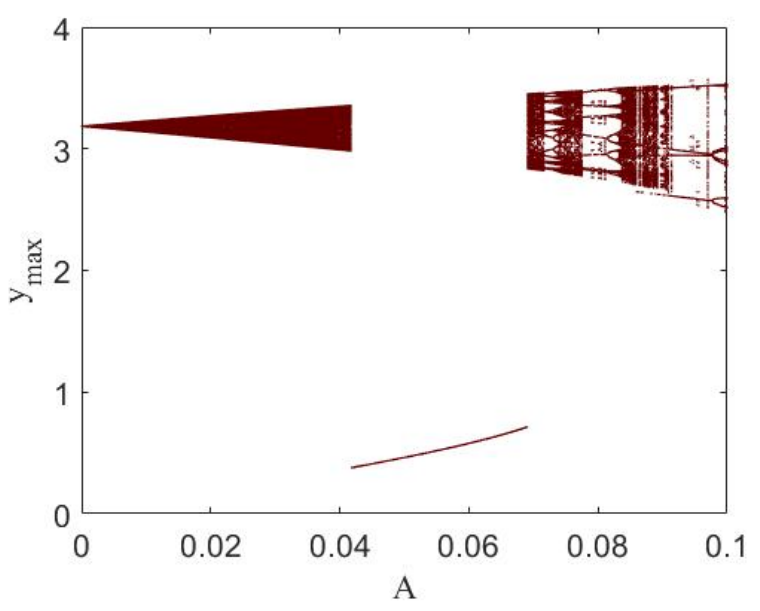

Fig. 3. Bifurcation diagram when changing parameter $A$ in system (6) with $\omega=0.5$. The initial conditions for every value of $A$ were $(0,0)$.

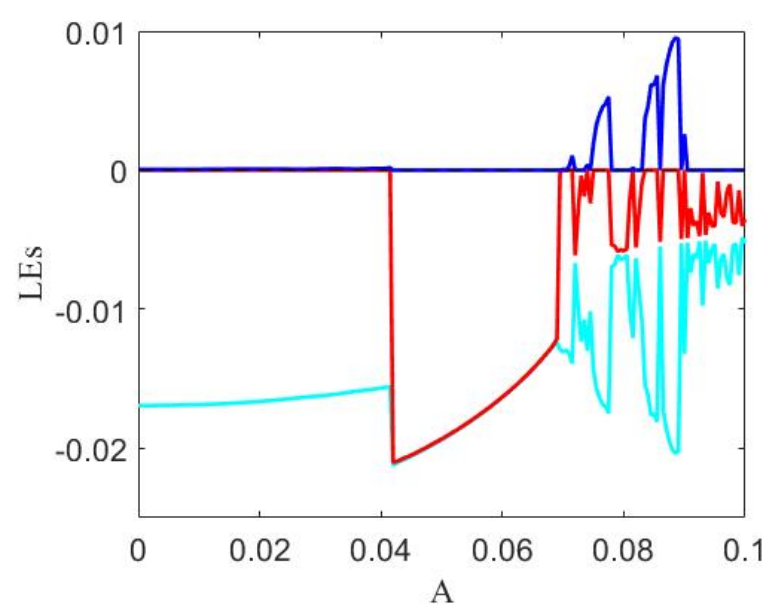

Fig. 4. The Lyapunov exponents' spectrum, corresponding to the bifurcation diagram in Fig. 3.
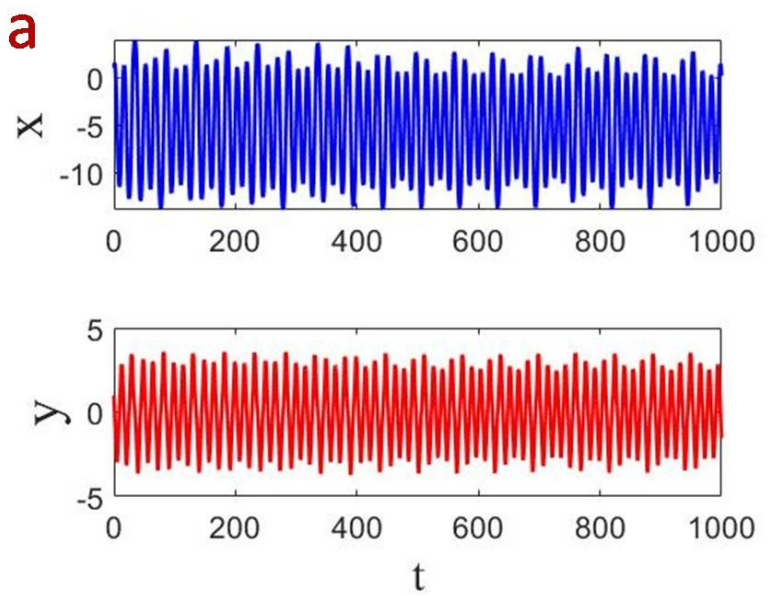

b

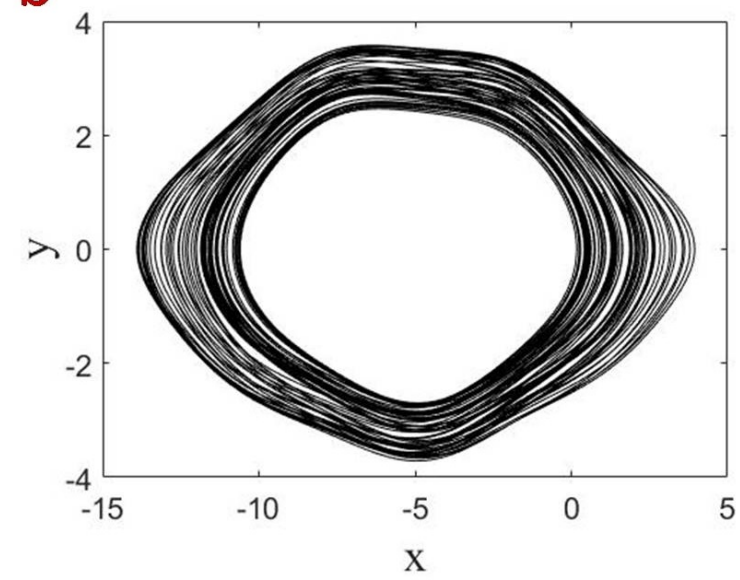

Fig. 5. a) Time-series and b) trajectory in system (6) for $A=0.1$ and $\omega=0.5$ for the initial conditions $(1,1)$. 


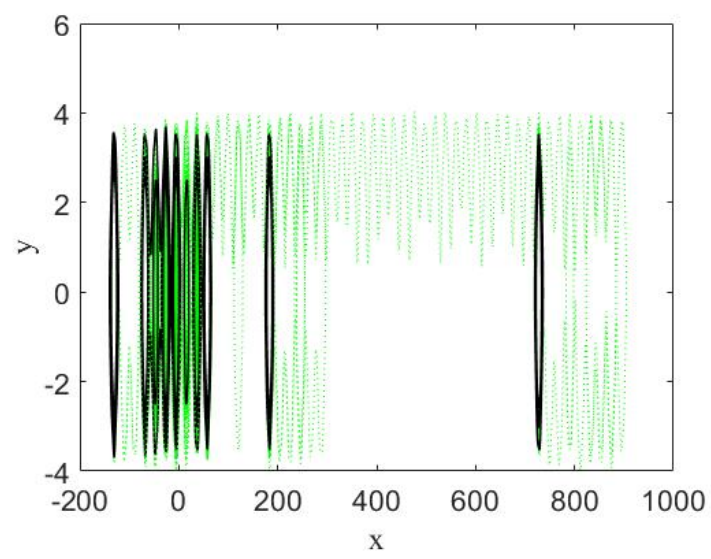

Fig. 6. Trajectories in system (6) for $A=0.1$ and $\omega=0.5$ for the same initial conditions used in Fig.1.
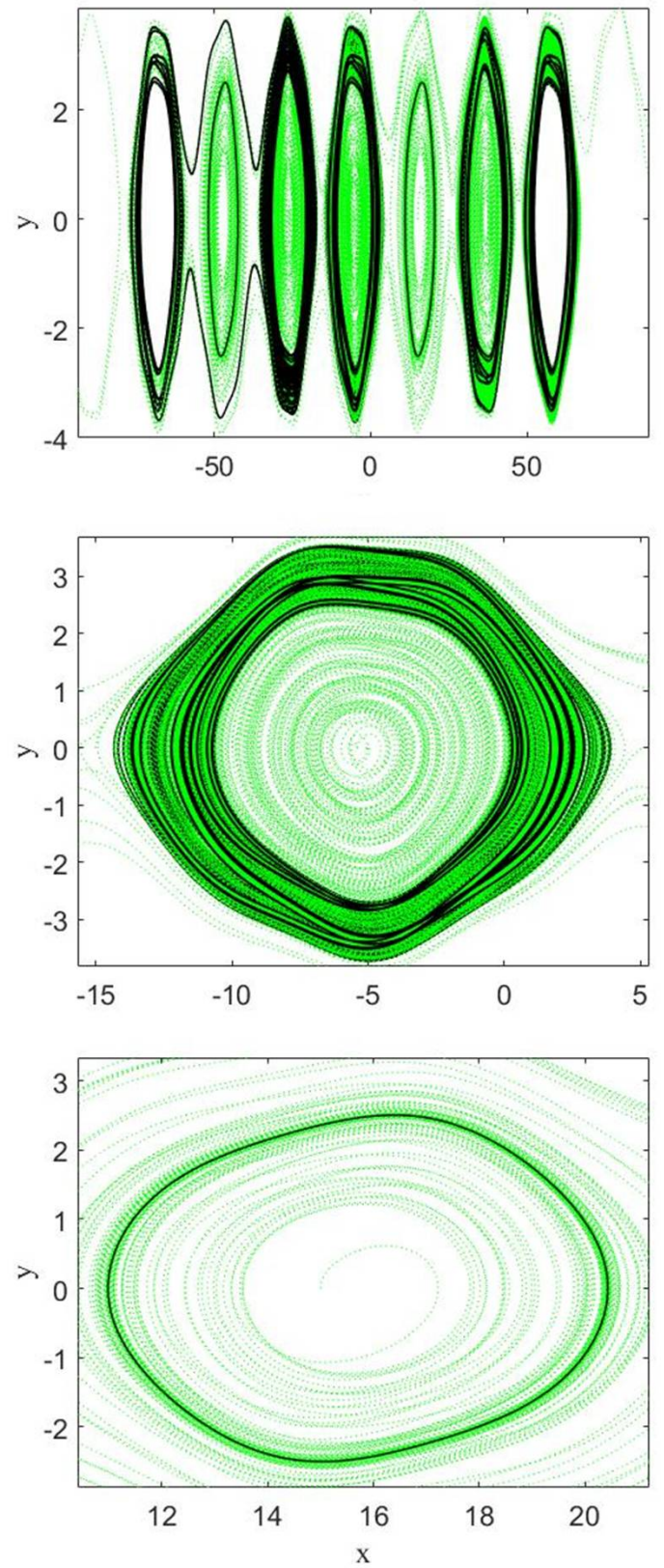

Fig. 7. Some zoomed parts of Fig. 6.

\section{Circuit Design}

Previous researches have described general methods in order to implement mathematical models using voltage-mode devices [42] and current-mode active elements [10]. It is possible to implement the forced chaotic oscillator (6) by using a circuit [43-51] as designed in Fig. 8. Two voltages at the capacitors $\left(C_{1}, C_{2}\right)$ are $X$ and $Y$. In Fig. 8, the value of $0.3 X$ has been realized by two inverting amplifiers $\left(U_{4}, U_{5}\right)$. Integrated circuits $U_{1}-U_{6}$ are TL084 operational amplifiers. It is noted that we have only presented the cosine transfer functions as two-port lumped circuits in Fig. 8. In fact, the cosine function in the circuit equations can be realized by using trigonometric function generator AD639 [52], [53]. For the designed circuit, we have selected $R_{1}=R_{2}=R=10 \mathrm{k} \Omega$, $R_{3}=R_{4}=R_{5}=100 \mathrm{k} \Omega, R_{6}=30, \mathrm{k} \Omega, C_{1}=C_{2}=C_{3}=C=$ $10 \mathrm{nF}$, and $f=0.795 \mathrm{kHz}$. PSpice trajectories in Fig. 9 show the circuit's chaos.

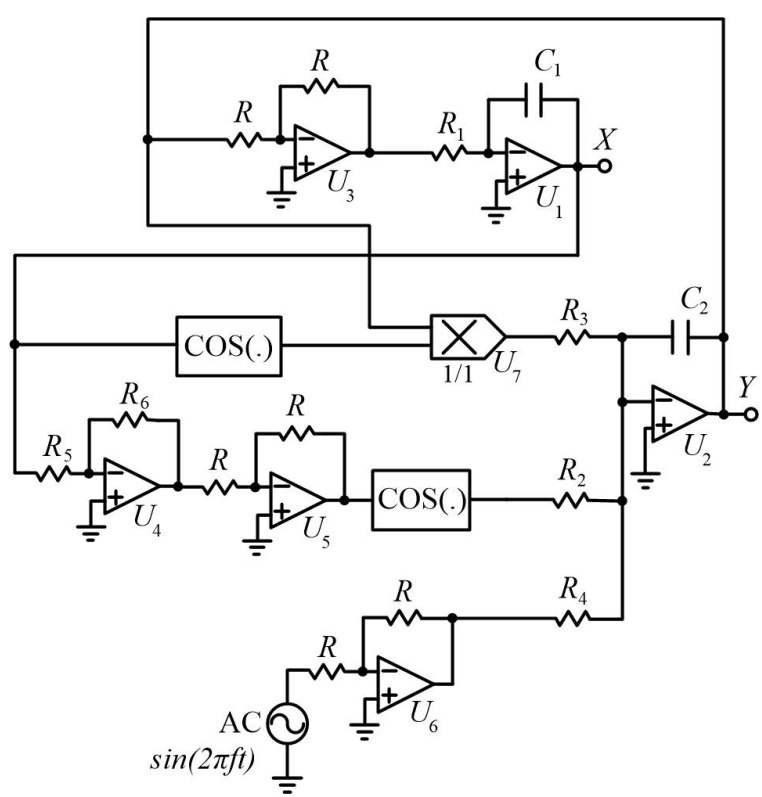

Fig. 8. The forced chaotic oscillator (6) emulated in a circuit.

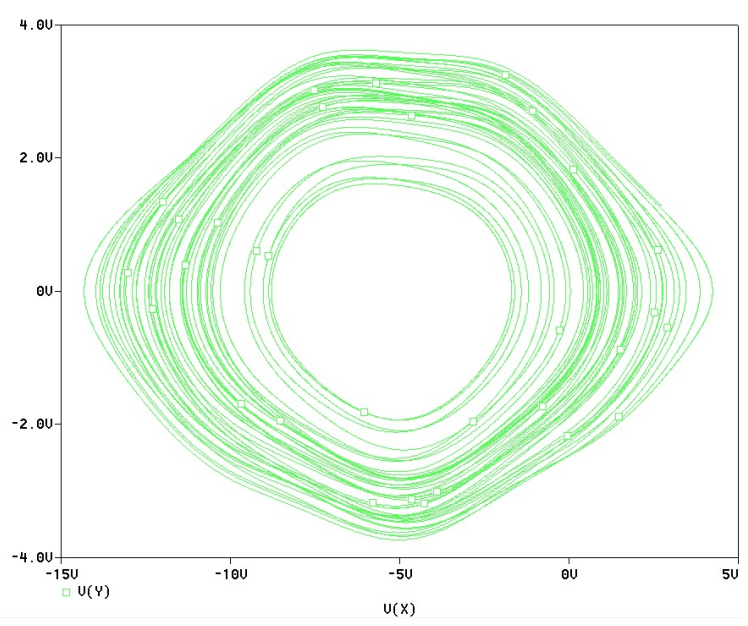

Fig. 9. PSpice trajectories displayed in the circuit. 


\section{Conclusion}

Introducing rare dynamical oscillators with unusual properties has been a hot topic in nonlinear dynamics recently. In this paper, we designed and investigated a new mega-stable oscillator. This new system had an infinite number of coexisting attractors (limit cycles and stable equilibria). Adding a forcing term to this oscillator a new oscillator obtained which was capable of showing very rich dynamical solutions torus, chaos, and limit cycle. The initial conditions in this system can escape neighboring attractors and settle down in unexpected far destinations. The forced chaotic oscillator was emulated in a circuit. However, we think due to saturation in the elements, it is difficult to obtain other attractors in the circuit results.

\section{Acknowledgments}

This work was supported by The Phenikaa University Foundation for Science and Technology Development.

\section{References}

[1] PISARCHIK, A.N., FEUDEL, U. Control of multistability. Physics Reports, 2014, vol. 540, no. 4, p. 167-218. DOI: 10.1016/j.physrep.2014.02.007

[2] SHARMA, P., M. SHRIMALI, M., PRASAD, A., et al. Control of multistability in hidden attractors. The European Physical Journal Special Topics, 2015, vol. 224, no. 8. p. 1485-91. DOI: $10.1140 /$ epjst/e2015-02474-y

[3] WEI. Z. Dynamical behaviors of a chaotic system with no equilibria. Physics Letters A, 2011, vol. 376, no. 2, p. 102-108. DOI: $10.1016 /$ j.physleta.2011.10.040

[4] JAFARI, S., SPROTT, J. C., HASHEMI GOLPAYEGANI, S. M. R. Elementary quadratic chaotic flows with no equilibria. Physics Letters A, 2013, vol. 377, no. 9, p. 699-702. DOI: $10.1016 /$ j.physleta.2013.01.009

[5] WEI, Z., ZHANG., W. Hidden hyperchaotic attractors in a modified Lorenz-Stenflo system with only one stable equilibrium. International Journal of Bifurcation and Chaos, 2014, vol. 24, no. 10, p. 1450127. DOI: $10.1142 / \mathrm{S} 0218127414501272$

[6] Molaie, M., JAFARI, S., SPROTT, J. C., et al. Simple chaotic flows with one stable equilibrium. International Journal of Bifurcation and Chaos, 2013, vol. 23, no. 11, p. 1-12. DOI: $10.1142 / \mathrm{S} 0218127413501885$

[7] GOTTHANS, T., PETRZELA, J. New class of chaotic systems with circular equilibrium. Nonlinear Dynamics, 2015, vol. 81, no. 3, p. 1143-1149. DOI: $10.1007 / \mathrm{s} 11071-015-2056-7$

[8] GOtThans, T., SPROTT J. C., PETRZElA, J. Simple chaotic flow with circle and square equilibrium. International Journal of Bifurcation and Chaos, 2016, vol. 26, no. 8, p. 1650137-1650147. DOI: $10.1142 / \mathrm{S} 0218127416501376$
[9] PETRZELA, J., GOTTHANS, T. New chaotic dynamical system with a conic-shaped equilibrium located on the plane structure. Applied Sciences, 2017, vol. 7, no. 10, p. 1-13. DOI: 10.3390/app7100976

[10] PETRZEla, J., GOTTHANS, T., GUZAN, M. Current-mode network structures dedicated for simulation of dynamical systems with plane continuum of equilibrium. Journal of Circuits, Systems and Computers, 2018, vol. 27, no. 9, p. 1-39. DOI: $10.1142 / \mathrm{S} 0218126618300040$

[11] JAFARI, S., SPROTT, J. C., PHAM, V.-T., et al. Simple chaotic 3D flows with surfaces of equilibria. Nonlinear Dynamics, 2016, vol. 86, no. 2, p. 1349-1358. DOI: 10.1007/s11071-016-2968-x

[12] SINGH, J. P., ROY, B. K., JAFARI, S. New family of 4-D hyperchaotic and chaotic systems with quadric surfaces of equilibria. Chaos, Solitons \& Fractals, 2018, vol. 106, p. 243-257. DOI: $10.1016 /$ j.chaos.2017.11.030

[13] MA, J., ZHOU, P., AHMAD, B., et al. Chaos and multiscroll attractors in RCL-shunted junction coupled Jerk circuit connected by memristor. PloS One, 2018, vol. 13, no. 1, p. 1-21. DOI: 10.1371 /journal.pone.0191120

[14] DANCA, M.-F., KUZNETSOV, N., CHEN, G. Unusual dynamics and hidden attractors of the Rabinovich-Fabrikant system. Nonlinear Dynamics, 2017, vol. 88, no. 1, p. 791-805. DOI: $10.1007 / \mathrm{s} 11071-016-3276-1$

[15] KUZNETSOV, N., LEONOV, G., YULDASHEV, M., et al. Hidden attractors in dynamical models of phase-locked loop circuits: limitations of simulation in MATLAB and SPICE. Communications in Nonlinear Science and Numerical Simulation, 2017, vol. 51, p. 39-49. DOI: $10.1016 /$ j.cnsns.2017.03.010

[16] LI, C., SPROTT, J. C., YUAN, Z., et al. Constructing chaotic systems with total amplitude control. International Journal of Bifurcation and Chaos, 2015, vol. 25, no. 10, p. 1-14. IDOI: $10.1142 / \mathrm{S} 0218127415300256$

[17] LI, C., SPROTT, J. C., AKGUL, A., et al. A new chaotic oscillator with free control. Chaos: An Interdisciplinary Journal of Nonlinear Science, 2017, vol. 27, no. 8, p. 1-6. DOI: 10.1063/1.4997051

[18] ZHANG, L.-M., SUN, K.-H., LIU, W.-H., et al. A novel color image encryption scheme using fractional-order hyperchaotic system and DNA sequence operations. Chinese Physics B, 2017, vol. 26, no. 10, p. 1-9. DOI: $10.1088 / 1674-1056 / 26 / 10 / 100504$

[19] YU, M., SUN, K., LIU, W., et al. A hyperchaotic map with grid sinusoidal cavity. Chaos, Solitons \& Fractals, 2018, vol. 106, p. 107-117. DOI: $10.1016 /$ j.chaos.2017.11.004

[20] CHEN, C., SUN, K., HE, S. A class of higher-dimensional hyperchaotic maps. The European Physical Journal Plus, 2019, vol. 134, no. 8, p. 1-13. DOI: 10.1140/epjp/i2019-12776-9

[21] PENG, D., SUN, K.H., ALAMODI, A.O. Dynamics analysis of fractional-order permanent magnet synchronous motor and its DSP implementation. International Journal of Modern Physics B, 2019, vol. 33 , no. 6, p. 1-15. DOI: 10.1142/S0217979219500310

[22] PENG, Y., SUN, K., HE, S., et al. Parameter identification of fractional-order discrete chaotic systems. Entropy, 2019, vol. 21, no. 1 , p. $1-27$. DOI: $10.3390 / \mathrm{e} 21010027$

[23] PENG, Y., SUN, K., PENG, D., et al. Dynamics of a higher dimensional fractional-order chaotic map. Physica A: Statistical Mechanics and its Applications, 2019, vol. 525, p. 96-107. DOI: $10.1016 /$ j.physa.2019.03.058 
[24] ZHOU, P., KE, M. A new 3D autonomous continuous system with two isolated chaotic attractors and its topological horseshoes. Complexity, 2017, vol. 2017, p. 1-7. DOI: 10.1155/2017/4037682

[25] ZHOU, P., YANG, F. Hyperchaos, chaos, and horseshoe in a 4D nonlinear system with an infinite number of equilibrium points. Nonlinear Dynamics, 2014, vol. 76, no. 1, p. 473-480. DOI: $10.1007 / \mathrm{s} 11071-013-1140-0$

[26] CHEN, M., FENG, Y., BAO, H., et al. Hybrid state variable incremental integral for reconstructing extreme multistability in memristive jerk system with cubic nonlinearity. Complexity, 2019, vol. 2019, p. 1-16. DOI: $10.1155 / 2019 / 8549472$

[27] CHEN, M., SUN, M., BAO, H., et al. Flux-charge analysis of two-memristor-based chua's circuit: dimensionality decreasing model for detecting extreme multistability. IEEE Transactions on Industrial Electronics, 2019, vol. 67, no. 3, p. 2197-2206. DOI: 10.1109/TIE.2019.2907444

[28] PROUSALIS, D. A., VOLOS, C. K., BAO, B., et al. Extreme multistability in a hyperjerk memristive system with hidden attractors. Chapter in Recent Advances in Chaotic Systems and Synchronization, Elsevier, 2019, p. 89-103. ISBN: 9780128162668. DOI: $10.1016 / \mathrm{B} 978-0-12-815838-8.00006-6$

[29] ZHANG, Y., LIU, Z., WU, H., et al. Two-memristor-based chaotic system and its extreme multistability reconstitution via dimensionality reduction analysis. Chaos, Solitons \& Fractals, 2019, vol. 127, p. 354-63. DOI: 10.1016/j.chaos.2019.07.004

[30] SPROTT, J. C. Elegant Chaos: Algebraically Simple Chaotic Flows. World Scientific, 2010. ISBN: 9812838821

[31] WANG, Z., ABDOLMOHAMMADI, H. R., ALSAADI, F. E., et al. A new oscillator with infinite coexisting asymmetric attractors. Chaos, Solitons \& Fractals, 2018, vol. 110, p. 252-258. DOI: 10.1016/j.chaos.2018.03.031

[32] LI, C., SPROTT, J. C., HU, W., et al. Infinite multistability in a self-reproducing chaotic system. International Journal of Bifurcation and Chaos, 2017, vol. 27, no. 10, p. 1750160. DOI: $10.1142 / \mathrm{S} 0218127417501607$

[33] SPROTT, J. C., JAFARI, S., KHALAF, A. J. M., et al. Megastability: Coexistence of a countable infinity of nested attractors in a periodically-forced oscillator with spatially-periodic damping. The European Physical Journal Special Topics, 2017, vol. 226, no. 9, p. 1979-1985. DOI: 10.1140/epjst/e2017-70037-1

[34] PRAKASH, P., RAJAGOPAL, K., SINGH, J., et al. Megastability in a quasi-periodically forced system exhibiting multistability, quasi-periodic behaviour, and its analogue circuit simulation. $A E U$ International Journal of Electronics and Communications, 2018 vol. 92, p. 111-115. DOI: 10.1016/j.aeue.2018.05.021

[35] TANG, Y., ABDOLMOHAMMADI, H. R., KHALAF, A. J. M., et al. Carpet oscillator: A new megastable nonlinear oscillator with infinite islands of self-excited and hidden attractors. Pramana, 2018, vol. 91, no. 1, p. 1-6. DOI: 10.1007/s12043-018-1581-6

[36] WEI, Z., PHAM, V.-T., KHALAF, A. J. M., et al. A modified multistable chaotic oscillator. International Journal of Bifurcation and Chaos, 2018, vol. 28, no. 7, p. 1-9. DOI: $10.1142 / \mathrm{S} 0218127418500852$

[37] TANG, Y. X., KHALAF, A. J. M., RAJAGOPAL, K., et al. A new nonlinear oscillator with infinite number of coexisting hidden and self-excited attractors. Chinese Physics B, 2018, vol. 27, no. 4, p. 1-6. DOI: $10.1088 / 1674-1056 / 27 / 4 / 040502$
[38] LI, C., SPROTT, J. C., KAPITANIAK, T. et al. Infinite lattice of hyperchaotic strange attractors. Chaos, Solitons \& Fractals, 2018, vol. 109, p. 76-82. DOI: 10.1016/j.chaos.2018.02.022

[39] LI, C., THIO, W. J. C., SPROTT, J. C. et al. Constructing infinitely many attractors in a programmable chaotic circuit. IEEE Access, 2018, vol. 6, p. 29003-29012. DOI: 10.1109/ACCESS.2018.2824984

[40] KAHN, P. B., ZARMI, Y. Nonlinear Dynamics: Exploration Through Normal Forms. Courier Corporation, 2014. ISBN: 0486780457.

[41] WOLF, A., SWIFT, J. B., SWINNEY, H. L. et al. Determining Lyapunov exponents from a time series. Physica $D$ : Nonlinear Phenomena, 1985, vol. 16, no. 3, p. 285-317. DOI: 10.1016/0167-2789(85)90011-9

[42] ITOH, M. Synthesis of electronic circuits for simulating nonlinear dynamics. International Journal of Bifurcation and Chaos, 2001, vol. 11, no. 3, p. 605-653. DOI: 10.1142/S0218127401002341

[43] BUSCARINO, A., FORTUNA, L., FRASCA, M. The jerk dynamics of Chua's circuit. International Journal of Bifurcation and Chaos, 2014, vol. 24, no. 6, p. 1450085. DOI: 10.1142/S0218127414500850

[44] XU, Q., LIN, Y., BAO, B., et al. Multiple attractors in a non-ideal active voltage-controlled memristor based Chua's circuit. Chaos, Solitons \& Fractals, 2016, vol. 83, p. 186-200. DOI: 10.1016/j.chaos.2015.12.007

[45] PETRZELA, J. Strange attractors generated by multiple-valued static memory cell with polynomial approximation of resonant tunneling diodes. Entropy, 2018, vol. 20, no. 9, p. 1-23. DOI: $10.3390 / \mathrm{e} 20090697$

[46] PETRZELA, J. Multi-valued static memory with resonant tunneling diodes as natural source of chaos. Nonlinear Dynamics, 2018, vol. 94 , no. 3, p. 1867-1887. DOI: 10.1007/s11071-018-4462-0

[47] RAJAGOPAL, K., LI, C., NAZARIMEHR, F., et al. Chaotic dynamics of modified wien bridge oscillator with fractional order memristor. Radioengineering, 2019, vol. 28, no. 1, p. 165-174. DOI: $10.13164 /$ re.2019.0165

[48] PETRZELA, J., KOLKA, Z., HANUS, S. Simple chaotic oscillator From mathematical model to practical experiment. Radioengineering, 2006, vol. 15 , no. 1 , p. 6-12. ISSN: $1210-2512$

[49] GOTTHANS, T., PETRZELA, J. Experimental study of the sampled labyrinth chaos. Radioengineering, 2011, vol. 20, no. 4, p. 873-879. ISSN: $1210-2512$

[50] PETRZELA, J., HRUBOS, Z., GOTTHANS, T. Modeling deterministic chaos using electronic circuits. Radioengineering, 2011, vol. 20 , no. 2, p. 438-444. ISSN: $1210-2512$

[51] YENER S. C., KUNTMAN, H. H. Fully CMOS memristor based chaotic circuit. Radioengineering, 2014, vol. 23, no. 4, p. 1140-1149. ISSN: 1210-2512

[52] SHEN, C., YU, S., LU, J. A systematic methodology for constructing hyperchaotic systems with multiple positive Lyapunov exponents and circuit implementation. IEEE Transactions on Circuits and Systems I: Regular Papers, 2013, vol. 61, no. 3, p. 854-864. DOI: 10.1109/TCSI.2013.2283994

[53] TANG, W. K., ZHONG, G. Q., CHEN, G., et al. Generation of n-scroll attractors via sine function. IEEE Transactions on Circuits and Systems I: Fundamental Theory and Applications, 2001, vol. 48, no. 11 , p. 1369-1372. DOI: $10.1109 / 81.964432$ 


\section{About the Authors ...}

Viet-Thanh PHAM graduated in Electronics and Telecommunications in 2005 at Hanoi University of Technology, Vietnam. He received the Ph.D. degree in Electronics, Automation, and Control of Complex Systems Engineering in 2013 from the University of Catania, Italy. His scientific interest includes applications of nonlinear systems, analysis and design of analog circuits, and FPGA-based digital circuits.

Dalia S. ALI received the B.S. in Mathematical Science from the Department of Mathematics/University of Baghdad and received the Ms.C. in Mathematical science from Department of Mathematics / College of Science for women / University of Baghdad, in 2012 and 2015 respectively. Her research interest includes adjoint operator, probabilistic Hilbert space, dynamical systems and their applications. In 2015, she joined the Department of Civil Engineering in Al-Mansour University college, as an Academic Staff member.

Nadia M. G. AL-SAIDI is a Professor in the Department of Applied Sciences, University of Technology-Baghdad-Iraq. She completed her Bachelor of Science and Master of Science degrees in Applied Mathematics, from Department of Applied Sciences-University of Technology, Baghdad, Iraq, in 1989, and 1995, respectively. She received her Ph.D. degree in Mathematics and Computer Application Sciences from Al-Nahrain University, Baghdad, Iraq in 2003. She joined the Institute for Mathematical Research (INSPEM), University Putra Malaysia (UPM) as a post doctorate researcher from 2008-2010 with the research project "Fractals in Cryptography". In 1989 she joined the Department of Applied Sciences, University of Technology as an Academic
Staff member. Prof. Dr. Nadia is the author of numerous technical papers since 1994, her research interests include: cryptography, fractal geometry, chaos theory, graph theory.

Karthikeyan RAJAGOPAL is presently working as an Sr.Research member and Professor in Center for Nonlinear Dynamics of Defence University, Ethiopia. He has completed his Ph.D. in Electronics and Communication Engineering with specializing in Chaos-based Secure Communication Engineering. His post-graduation was in embedded system technologies with emphasis on real-time targets programming. He has over 100 international journal papers indexed in SCI and his present research areas include fractional order nonlinear systems and control, time delay systems, FPGA and LabVIEW implementations of fractional order systems.

Fawaz E. ALSAADI received his Master degree from Computer Science, School of Engineering and Computer Science, The University of Denver, USA. He received his Ph.D. from Computer Science, Engineering, University of Colorado Colorado Springs, USA. He is currently Assistant Professor in Department of Information Technology, Faculty of Computing and Information Technology, King Abdulaziz University, KSA.

Sajad JAFARI (corresponding author) was born in Kermanshah, Iran, in 1983. He received his BSc., M.S., and Ph.D. degrees in Biomedical Engineering in 2005, 2008, 2013 from Biomedical Engineering department, Amirkabir University of Technology, Tehran, Iran. He is currently an Assistant Professor in there (since 2013). His research interests include artificial intelligence, optimization, pattern recognition and especially nonlinear and chaotic signals and systems. 